\title{
Human Communication in a Digital Age: Perspectives on Interpersonal Communication in the Family
}

\author{
Ijeoma Onyeator $^{*} \quad$ Ngozi Okpara \\ School of Media and Communication, Pan-Atlantic University, KM 52, Lekki- Epe Express way, Ibeju-Lekki, \\ Lagos, Nigeria
}

\begin{abstract}
With the evolution of the digital era characterized by human-computer interaction, there has been a marked difference in the manner in which humans communicate. This revolution in patterns of communication from face-to-face interpersonal contact to human-machine communication is enabled by the affordances of technology. Using the family unit in Nigeria as a case study, this study examines the changes in one-on-one communication among family members, as a result of constant engagement with digital technologies. It conceptualizes the family as a unit comprising two or more persons living together who are related by blood, marriage, adoption or social affiliation. The survey research design was adopted, and structured questionnaires were administered on 370 respondents in the 37 local council development areas of Lagos state, south west Nigeria. Findings indicate that most family members lose interest in communicating interpersonally with each other due to constant engagement with technologies. The study also finds that reduced cues and non-selfdisclosure often pulls family members apart rather than bringing them close together. Key recommendations include that strong family relationships should transcend the mere acquisition of digital competencies, tools and technologies. It suggests that the attributes at the core of humanness should not be lost as a result of constant engagement with communication technologies.
\end{abstract}

Keywords: human communication, humanness, digital communication, communication devices, digital age.

DOI: $10.7176 / \mathrm{NMMC} / 78-06$

\section{Introduction}

The extent to which humans communicate is a great part of what makes them human. Human beings have an innate desire to articulate their needs, desires and interests. They also experience a host of feelings and emotions like joy, fear, hate, pity, anger and love; all of which are communicated through a range of gestures, speech or in written form. Communication is therefore central to human existence and serves as the channel through which humans interact with one another. Through communication, individuals establish relationships and find companionship. For this reason, Daramola's (2012) definition of human communication as the social interaction that occurs between persons through the exchange of messages remains apt.

At the heart of human communication is the fulfilment of the basic need for association and interaction. Human communication strengthens the feelings of togetherness among people through mutual understanding DeVito (2009). The concept human communication also includes all the collective activities involved in the sharing of ideas, facts and data from one person to the next. Human communication through the decades involves development of signals and gestures (Smith, 1993), before humans developed the spoken word. 50,000 years after humans began to speak, writing was invented. 5,000 years after, printing was invented. 500 years after, the first computer was invented. Since then, the network of digital devices has grown in leaps and bounds from digital media tools to all sorts of computing devices (Sellen, Rogers, Harper \& Rodden, 2009). However, while it is established that humans must communicate to exist in their world, the rules of engagement have changed with digital communication becoming the language of the new digital world. In the old order, the human adult uttered at least 16,000 words a day, mostly through verbal exchange (Neuman, 2012). However, humans now relay their most intimate thoughts and emotions over communications media. The consequence of this is that the interface between person and machine has drastically reduced the desire for physical presence. For instance, face-to-face conversations to a large extent have given way to telephones, mobile phones, smart phones, the internet and other digital technology. Nearly all forms of interaction among humans are communicative acts that are digitally enabled, observable and recordable by others (Global information society watch, 2014). What this means is that technology underpins almost every aspect of human life, resulting in a reliance on them to communicate with one another. The effect of this communication revolution on personal communication in the family is of keen interest to this paper.

\subsection{Features of the Nigerian family system}

Early conceptualizations of the family in the Western world classified it as the smallest social unit of the society comprising a married father and mother with biological children. Loveless and Holman (2007) describe the traditional nuclear family as a small group characterized by couples of the opposite sex who are legally married and reside in the same dwelling. However, Enrique et al., (2007) argue that families can also be formed by the 
unofficial union of people endorsed neither by faith nor the state. Such people share close emotional attachment and often live together. However, across the African content, families are usually large as a result of the extended family structure. This includes countries like Nigeria where families are described as large social groups (Adeoye \& Adeoye, 2010). As a result of multiple ethnic and ancestral ties, extended family members (like uncles, aunties, cousins, nephews and nieces) most times, have far greater influence on nuclear family members, in comparison to family systems in the westernized world. Some scholars describe the structure of Nigerian families as extensive rather than extended, because they are characterized by a multiplicity of primary familial relationships (Labeodan, 2005). In recent years, Odu et al., (2017) argue that new characterizations of Nigerian families include other social units which have alternative structures to the traditional families. These include family environments with at least one child and one parent living in the same dwelling; couples of opposite sexes with no children; couples living with adopted or non-biological children and couples who have no children.

Traditional Nigerian families are categorized as patriarchal in terms of authority, which implies that the father is considered the head and plays a dominant role. However, this structure varies among the country's 250 ethnic groups and it is common place to discover clans that are matriarchal. Nigerian families have traditionally placed importance on having children because culturally, it is believed that children will provide support for parents in their old age (Ogunjuyigbe, Ojofeitimi \& Liasu, 2009). Relationships are mostly guided by a strict system of seniority, while rules and norms are often organized around male egoistic values. Furthermore, Obayan (1995) argues that there is a tendency for Nigerians to recreate surrogate family units, linked more by social interaction than kinship ties. This interaction may be as a result of a common ethnic origin (like village meetings and associations); area of residence (like estate associations) and professional ties (like unions) etc. The flow of information in Nigerian families is characterized as mainly downward (from parents to children). However, with increased westernization and the spread of urban culture, certain cultures have given way to a system where flow of information is upward - from children to parents. It is from this understanding of the Nigerian family system that this paper examines interactions among its participants.

\subsection{Statement of the problem}

As far back as the 1980's sociologists and scholars of communication have been concerned about the apparent changes to family life, particularly in countries like Nigeria where family, culture and communication are intertwined. While examining this trend, some scholars elaborated a number of reasons for changing communication patterns among family members including: westernization, socialization, isolation of family members from extended family support; greater involvement and commitment of mothers outside the home; the engagement of the services of strangers to look after younger members of the family; and diminishing authority of fathers (Durojaiye \& Ipaye, 1983; Watzlawick et al., 2014). Top on that list however, were the changes in communication patterns associated with technological development. These technologies have not only opened up new communication channels for members of the family to interact, but they have also inspired a new communication culture, loosely termed 'digiculture' in scholarly circles (Creeber \& Martin, 2009). This new culture has disrupted the family's traditional social interaction structure, prompting them to perform new communication rituals, such as the acquisition of digital literacy or electracy. This involves learning to use technology and increasingly, humans are striving to acquire the competencies needed to master the new digital tools that drive the human communication process in a digitized society. The acquisition of these competencies is vital, as it has been argued that an individual must acquire, maintain and continually develop digital skills if he or she is to remain a critical citizen of the new world (Norwegian Ministry of Modernization, 2009; Dunu \& Ugochukwu, 2015). The new world citizens consist of the 'digital natives' who are born into this new culture of mediated communication, and the digital immigrants who adopt this culture after undergoing the process of learning, training and re-training (Martin, 2008). The presence of these two genres of citizens in the family has altered family life, as members are increasingly using the new skills they have acquired to regulate their relationships. With more members of the family joining the networked society, learning to use digital technologies is beyond vital, but an essential life skill.

The format of messages shared among family members has also changed. The new communication protocol is less oral based; instead relying heavily on messages that are constructed and sent in form of symbols, signs and texts to computer/phone screens. Today, whether in the same physical space or separated by miles, family members are relying less on oral forms of communication that require them to communicate face-to-face. Information can now be exchanged both in a synchronous manner (such posts and texts in on-line chat rooms) or asynchronous (where messages are not necessarily exchanged at the same time such as e-mail and text messages). Under the new rules of engagement, personal characteristics and identities can be hidden and only revealed if and when the individual chooses. Anonymity is also enabled as a result of the distance between participants. With all this change, there is a growing debate about whether digital literacy (which is spurred by the new communication culture) brings people together or pulls them apart. This separateness versus 
togetherness discourse is not new, but his paper contributes to this discourse by observing patterns in the context of the Nigerian family.

\subsection{Justification}

While most research on in-home technologies have concentrated on television and its related technologies, the literature also recognizes the importance of studying the role of newer media technologies (Caron et al., 1989; Morrison \& Krugman, 2010; Carlson \& Lewis, 2015). The family provides an important context for examining the effect of the entry of personal computing via laptops, personal computers, Ipads and mobile phones in the home. Therefore, this research looks to family members to determine how home-life is altered by various forms of personal computing.

\section{Literature Review}

\subsection{Being Human: A Conceptual Framework}

Humans are understood not only through their existence but through actions and interactions (Mara, 2007). The ability to reason and communicate thoughts distinguishes humans from all other beings. However, in an attempt to conceptualize humanness, other traits are identified to include: the development of complex social behaviour as well as relationships and bonds. Humans are social animals, but this in itself is not the essence of humanness; as many other species in the animal world display a form of social behaviour. For instance, ethologists have found that in lower animals, the non-verbal cues associated with mating rituals, playing, hunting and finding food are referred to as social behaviour (Tomecek, 2009). However, what is significant about the social behaviour of humans is the manner in which their society has evolved and the mechanisms through which social order is sustained. One milestone achievement for humanity is the development of systematic oral and written language (Bukeridge, 2009). Aristotle laid the foundation for understanding true humanness through the recognition of human virtues like morality, compassion, cooperation, courtesy, creativity, enthusiasm, forgiveness, honesty, truth, justice, love, generosity, loyalty, moderation, modesty, patience, tact, understanding, and tolerance. These are virtues associated with humanity alone and expressed in the course of face-to-face interactions among people in small or large groups.

Humans communicate introspectively as in the case of intra communication; and with others as in the case of interpersonal, group and public communication (Hewitt, 2011).

Interpersonal communication can occur in the workplace or in social groups. But the foundation of interpersonal interaction is often traced to the family - the basic unit of human life comprising people who interact in small groups. Interpersonal communication in the family context therefore includes but is not limited to face to face interactions among spouses, parents, children, siblings as well as other blood relatives. Within this small social institution, individuals learn to communicate, exchange messages and develop a sense of values through interaction with other family members (Viceno, 2004; Flanja and Gaz, 2011). They form close associations by meeting physically to share meaning and messages. This promotes bonding and affinity through the use of spoken words, gestures, eye contact, accent, vocal cues, non-vocal cues and touching. It enables messages to be openly shared, overheard and repeated to third parties with complete accuracy. There is also full disclosure of identity; speakers take turns and the communication among them is often synchronous because messages are exchanged at the same time. Interpersonal communication is therefore a symbolic process through which individuals maintain close relationships. Such frequent personal interactions are part of a healthy relational process which keeps human relationships going. During such close interactions, humans observe each other to pick up visual, verbal as well as non-verbal cues from the other person(s). In the process, they use their natural sensory organs including facial expressions, eye contact, body language and posture as well as gestures to communicate with others. The proximity and physical presence also afford humans the ability to naturally bond with each other. Furthermore, social psychologists argue that the physical presence of others during interaction influences message perception, cognition, decision making and action (Spape \& Rajava, 2014). They argue that such human characteristics enhance the communication experience. However, the physical presence of humans is increasingly mediated by communication devices which have altered not just the communication process, but human behaviour as well.

\subsection{The Dynamics of Human-Machine Interaction}

The initial machines made by man were time saving devices designed to take the physical strain out of laborious tasks. Early human-machine interaction was therefore more about using machines to perform mundane monotonous chores (Neuman, 2012). Following several experiments, clinical psychologists argued that research into brain activities - that which transpired inside the human mind - was an important guide for early computers. Machines were programmed to model human behaviour, but the emphasis what more on efficiency than interaction. By the $1990 \mathrm{~s}$, there was greater focus on how users with the aid of machines could interact better with each other. Researchers began to devise ways of connecting groups of users via communication networks, 
using machines like computers. However networked computers have encroached deeply into human personal spaces, by being embedded in everyday objects. These included household appliances, gadgets worn on the body; electronic devices carried in pockets and bags and more recently, to devices implanted within the human body. Research on the role of computer mediated technologies suggests that such technologies facilitate social interaction through group viewing and bulk message sharing Morrison and Krugman (2010). As a result of the proliferation of technologies, humans now live with technologies. Interactivity and hyper connectivity became buzz in response to the rapid availability and assimilation of entirely new ways to communicate. This led many researchers to argue about the dangers of techno-dependency. While these arguments are not new, this paper contributes to this discourse by shifting the research focus from the harmful effects of computer-mediated interaction in the digital era, to addressing what it means to be human when everything in the new digitized world is supported, augmented and driven by technology. It is from this understanding that the paper argues for a more human-value led approach to the many issues that are triggered by the rapid and evolving sphere of digital communication. The underlying question guiding this research is therefore: how have communication technologies influenced human communication in the family and have such technologies enhanced the ability of humans to communicate ethically?

\subsection{Communicating in a digital world}

Communication technologies facilitate human interaction and the rapid exchange of information and messages among people who are sometimes in different time zones. (Georgiadou, 1995; Ramanujam, 2008; Daramola, 2012). Such communication devices include computing devices, telephones, mobile phones, email, the Internet, social media and digital technologies. It is important to note that for the purpose of this study, all forms of communication enabled by a technological medium will be referred to as communication devices. However, the analysis focuses on the use of social media applications including WhatsApp, Facebook, Twitter and Instagram. Hancock, Thom-Santelli and Ritchie (2004) suggests that new communication devices allow communicators to interact with each other without sharing the same physical space. The ability to connect people in spite of the lack of physical co-presence is one of the strongest affordances and capabilities of new communication technology. Technology has therefore played an important role in the lives of humans uniting them in ways that were unimaginable a decade ago.

For instance, technological advances have made it easier for humans to access many people anywhere on the planet instantly and simultaneously. They compress space and time, placing control of information in the hands of the user. Toma et al., (2016) argue that humans are increasingly taking advantage of the affordances and features which technology offers. For instance, texting and tweeting have become the more dominant forms of interpersonal communication among family, friends and colleagues (Harper, et al., 2008). The speed of such platforms makes them almost the natural choice for keeping in touch. In another study, Smith et al., (2014) observed adult mobile culture in the United States and discovered that Americans produce over 184 billion text messages per month. Stewart, Dainton, and Goodboy (2014) also recognized the ubiquitous use of Facebook (FB) and other social networking sites among college students, teenagers and couples in the maintenance of close relationships.

News groups, website, forums and boards have transcended the traditional radio, television and mass media channels. Furthermore, Instagram, the mobile photo- sharing application has a global user base of 150 million people. This technological device affords its users the opportunity of achieving 'Instafame' - the condition of having a relatively great number of fans or followers on the application (Marwick, 2015). Instagram enables uses to represent themselves in a variety of ways using computing tools embedded in the software. Many of such internet enabled applications are visual mediums, which encourage humans to use images rather than written self- descriptions to express themselves. Dijck (2008) traced the traditional purpose of analogue photography to the preservation of cherished family memories and moments in time. Today however, online self-portraits (selfies) are omnipresent and tell the constructed stories of the present. It can therefore be deduced that communication devices have stimulated brand new ways of thinking, organizing, learning and more importantly connecting. It is these transformations in connections and interaction that has led many scholars to suggest that man is gradually losing his humanness (Pichevski, 2003; Neher \& Sandin, 2007; Watkins, 2012). Another major criticism of the digital era is that the challenges of intercultural contact are magnified. In spite of these criticisms, technologies have become a part of human culture, community and identity. Perhaps this is why McLuhan (1994) argues that communication devices are the extensions of man. With the dominance of human communication by networked computers, key communication scholars like McLuhan (1994) and McQuail (2005) also found that the human person exists in a global village where rules of social engagement are primarily mediated by communication technologies. The phrase global village or globalized world often refers to hyper connectivity which is enabled by communication networks that bring people together from any location and at any time. It shrinks the globe in time, transcending physical and geographical boundaries. Unlike the affordances of traditional radio and television which enabled the shrinking of the globe in the 1970s, new technology has 
morphed with the internet rapidly emerging as platform of convergence. Many of its features (email, newsgroups, chat rooms, boards, and websites) were added on in the new millennium.

Today, the internet has become pivotal in providing novel experiences of mediated interaction with formats ranging from text-based interaction (e.g. Twitter), to those that allow semi- audio-visual communication (e.g. Skype, face time, Instagram video, Facebook video). Furthermore, mobile telephony and smart-phones have extended the reach of the internet, making mobile culture a way of life, a part of human society and possibly physiology as techno-self scholars predict (Harper, Rodden, Rogers, \& Sellen, 2008). Perhaps this is that Watkins (2012) means when he argues that technologies have become not just a crucial part of communications culture but human communication identity.

Mobile phones are also the primary medium of internet access in Nigeria, with mobile phone use growing massively from almost nothing in 2000 to close to half of the population in 2012 and three quarters of the population by 2016 (Nigerian Communications Commission Report, 2016). However, there are those who criticize the impressive statistics attributed to access to communication technologies particularly in the developing world (Maele, 2003). For instance, the Global Information Technology Report (2012) indicates that hyper connectivity is the key differentiator between the information-haves and the have nots. Issues pertaining to these shortcomings particularly on the African continent exceed the scope of this paper but are dealt with extensively in the works of Maele (2003); Mutula (2005); Mutula (2008); and Russell and Steel (2013).

\subsection{Theoretical framework}

This paper is anchored on the Diffusion of Innovations (DOI) theory. The theory seeks to explain how over time, new ideas, inventions, technologies, attitudes or practices spread through a specific population or members of a given social system. In the context of this study, new technologies continue to permeate the society rapidly, expanding man's capacity to communicate with his fellow man. This implies that diffusion is accomplished because of the extent to which new communication technologies are adopted. Scholars like Aina (2003) argue, that innovations are frequently diffused by human agents. For this reason, this work is also anchored on the theory of social construction. Social agents play an important role in the spread of new technologies, firstly because the adoption decision is a mental process through which individuals possess knowledge of an innovation before deciding to adopt or reject it. They also decide whether or not to pass on the information regarding an innovation to other humans. They decide on how to use that technology, ethically or otherwise. Furthermore, technology in itself is values-neutral. This means that any study of communication technology must consider the key role of human agents. Therefore, while studies adopt the diffusion of innovations and technological determinism in the study of digital technologies (Achakpa-Ikyo \& Ogaba-Egba, 2016), the present work suggests that researchers should go beyond measuring diffusion and adoption as the sign of penetration. Rather, true diffusion of innovations is achieved when technologies are seen as a means to help and not hinder the human communication process. One way to measure this to gauge if communications and interactions are done ethically.

\subsection{Communicating Ethics in a Digital Era}

Mara (2007) argues that human actions once performed do not vanish without trace; rather they leave a moral footprint. In the context of this work, while technology empowers humans to communicate in a number of ways, their communicative behaviours should be governed by ethical principles. Hastily constructed messages sent into cyberspace without deep thought or reflection is a major source of misunderstandings in human relationships. Such information is stored in permanent electronic archives and easily retrievable by all parties. For this reason, it is important for communication technologies to be used in a moral and ethical way. Similarly, Neher and Sandin (2007) argue that the digital world is in dire need of an ethical sheriff to monitor the activities of unethical communicators. They argue that unlike the pre-digital age where individuals had greater control over the information shared or disseminated to others, communication devices allow information regarding people's locations, purchases, preferences, and even genetic susceptibilities to be tracked, processed and stored. Early proponents of dialogical ethics (Levinas, 1950; Rogers, 1970) suggest that the physical absence of one communicator makes it difficult to connect ethically with the person at the other end of the device. For instance, Buber (1965) suggests that an imposter who has taken on the identity of another person in a chat room is difficult to detect or control. Extending this argument, Rana (2018) states "there is a difference between a conversation that flows and authentically bounces between two different people and one that is flat, transactional, and only occurs to serve a purpose". Once the interaction becomes mediated, it is easy for non-verbal cues to be lost along the communication channel.

\section{Methodology}

The study used a quantitative research method and employed the survey research design. Surveys are one of the most common types of quantitative, social science research methods. In the survey research design, a sample of 
respondents is selected from a population and a standardized questionnaire is administered to them. In the present study, 360 structured questionnaires were used as the instrument of data collection from respondents in Lagos state, south-west Nigeria. Furthermore, Rouse (2014) argues that a digital divide typically exists between those in cities and those in rural areas. For this reason, participants who reside in the city were chosen because the population comprises Urban families who have access to the medium. Mutefa \& Tapera (2018) described the utility of the survey research method. They found that when a researcher establishes that certain factors are associated with a problem, a survey is used to establish the extent to which a particular factor causes or contributes to the problem. Surveys also provide a high level of general capability in representing a large population. The research used the purposive sampling technique. Given its uniqueness to the area of study, purpose sampling was considered to be the best technique in order to collect data from the population members with access to new communication technologies as well those who are heavy users of the medium. A fifteen (15) item questionnaire was issued to selected respondents within Lagos State south west Nigeria which is the study area. Lagos is made of 37 local council development areas (LCDA's), thus, in each council ward ten respondents were administered the research instrument which gives a total of 370 respondents. No questionnaires were returned from one of the LCDA's which brought the total number of responses to 360 .

\section{Findings and Discussion}

Fig. 1 below shows that a significant majority of total respondents 157 (44\%) use WhatsApp as a social mobile platform while $136(38 \%)$ use Facebook. The data also reveals that only 47 (13\%) of total respondent and 20 (5\%) of the total respondent use Twitter and Instagram respectively. This implies that WhatsApp is the most popular social media platform readily available to people in the research area:

Fig. 1. \& fig 1.1 Usage of social media

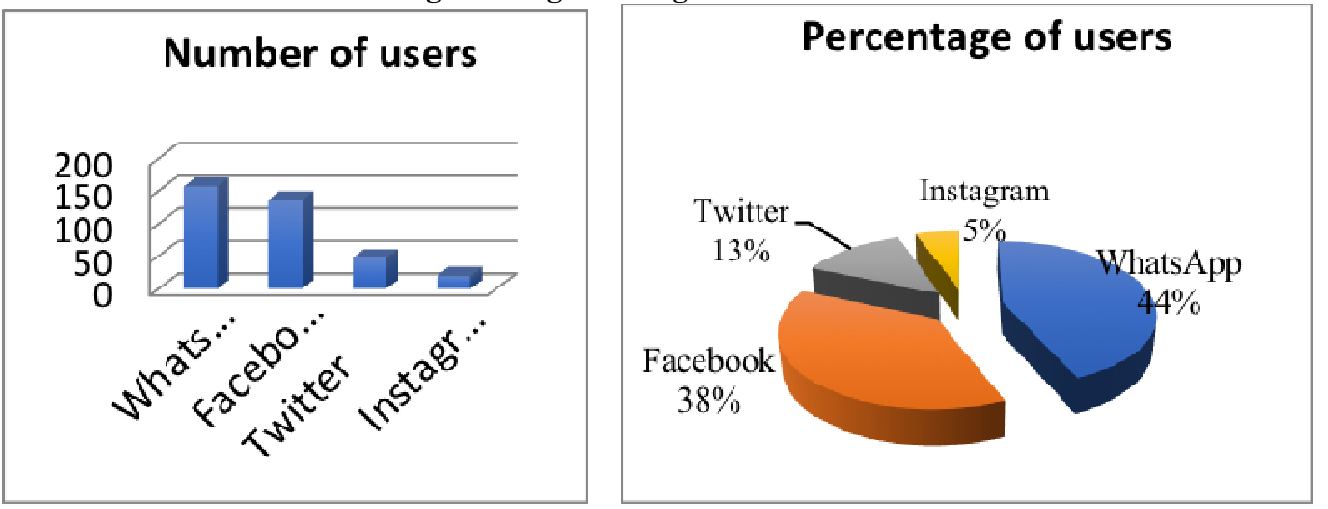

Data from Fig. 2. implies that all the respondents use the Internet frequently, and many spend over one hour online each day to the point that it interferes with their interpersonal communication with family members.

Fig. 2. Percentage of average time spent online

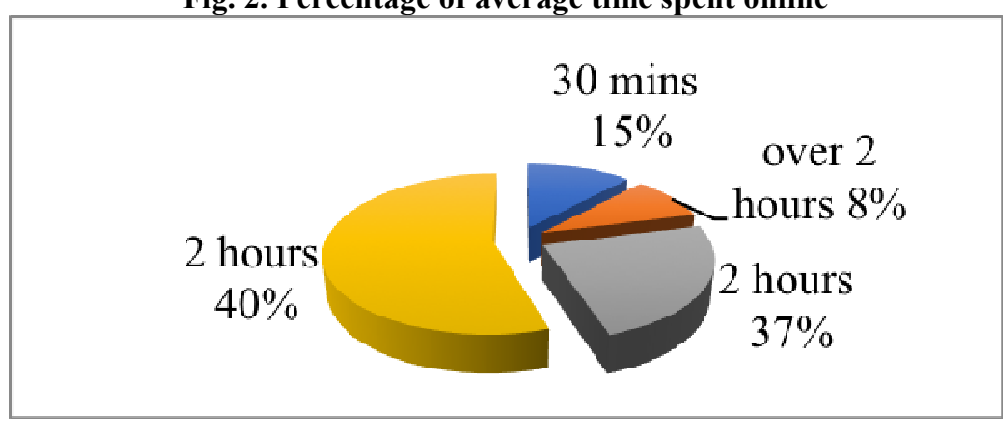

In Fig.2, data revealed that $37 \%$ spend about 2 hours online on a daily basis and majority of the respondents were teenagers. This group were found to becoming disconnected from family members because of their constant online presence. Many of them talked about spending a lot of time on dating sites, gaming sites and betting sites. 10 respondents in this category also talked about spending much time on Snap Chat, but there were not enough comments to analyze this social media application as a main research interest in this study. Fig. 3 shows that all the respondents have access to the internet via communication technologies. 
Fig. 3. Percentage spread of access to communication devices

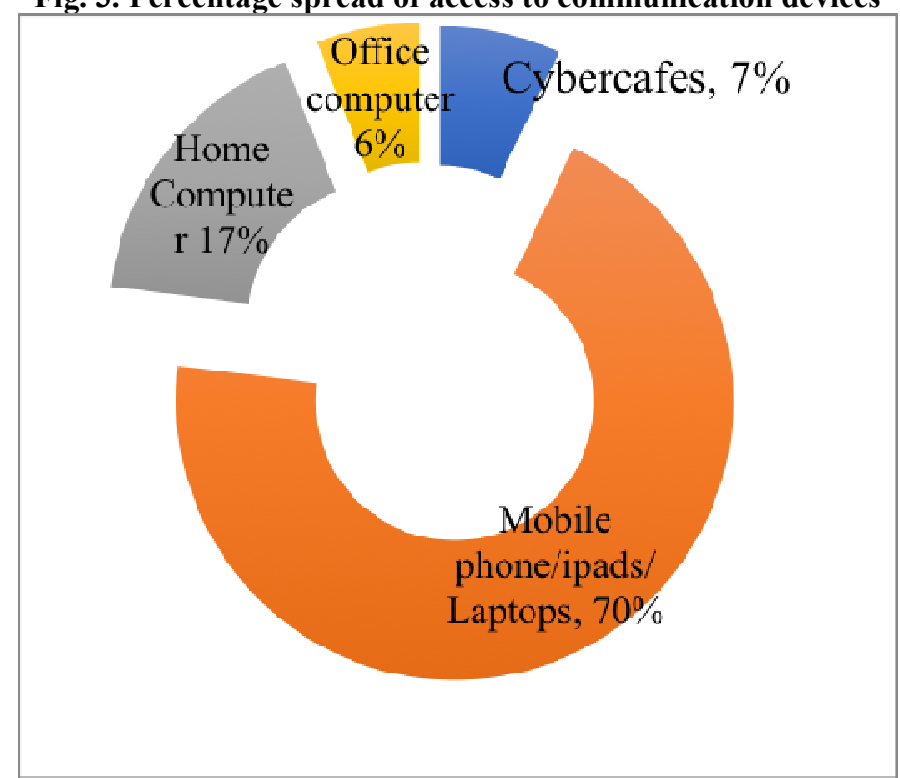

Fig. 3 shows that majority of respondents (70\%) accessed the internet on mobile phones, laptops and iPads. This group of respondents also talked about carrying their gadgets around the house to keep abreast of happening online and to stay in touch with their online relationships. Spouses in this category also complained about their partner's social media use including constant chatting with friends online and spending a significant amount of time browsing various social media websites. Such acts interfered with their interpersonal communication between the couple and also led to loss of interest in communicating with other family members.

Respondents were asked if heavy usage of mediated communication reduces personal communication and interaction within the family. Their responses are captured in fig. 4 below:

Fig. 4. Percentage spread of access to communication devices

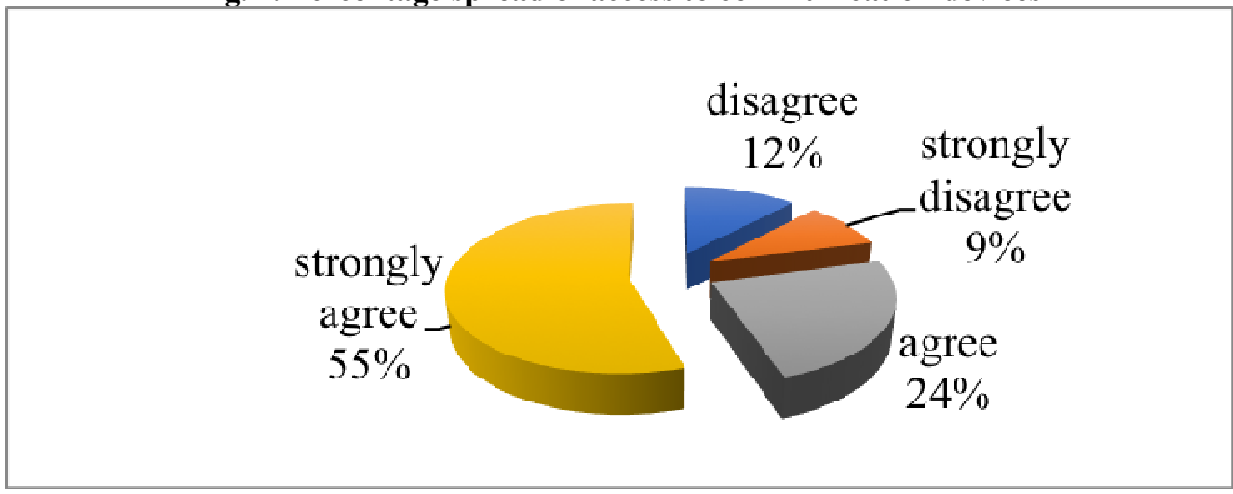

Fig. 4 shows the percentages of those who feel there is reduced personal communication and interactions as a result of mediated communication. It shows that $55 \%$ total respondents strongly agreed to this assertion. $24 \%$ agreed while $9 \%$ strongly disagreed. Respondents were asked if their various communication devices have created a gap in interpersonal communication in the family. Responses are analyzed in Fig. 5. 
Fig. 5 Percentage of respondents who feel technology created a gap in interpersonal communication in the family.

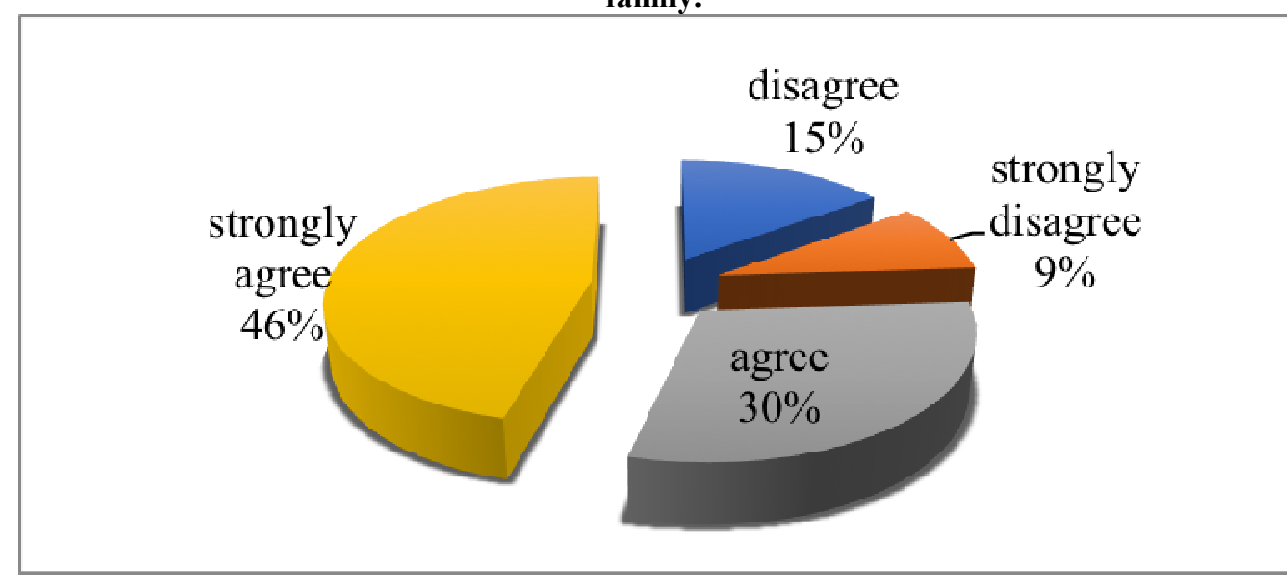

While $46 \%$ strongly agreed with this assertion only $9 \%$ strongly disagreed and these findings are as relevant today as they were over two decades ago, when studies on computer mediated technologies in the home, were conceptualized as decreasing social interaction, particularly within the household (Robertson, 1971; Caron et al., 1989; Haddon, 1992; and Vitalari et al., 2001).

Respondents were also asked if reduced face-to-face communication has a negative effect on members of the family in terms of the strength of their bond. Fig. 6 show below shows their responses:

Fig 6. Percentage of respondents who feel face-to-face communication has a negative effect on family bonding

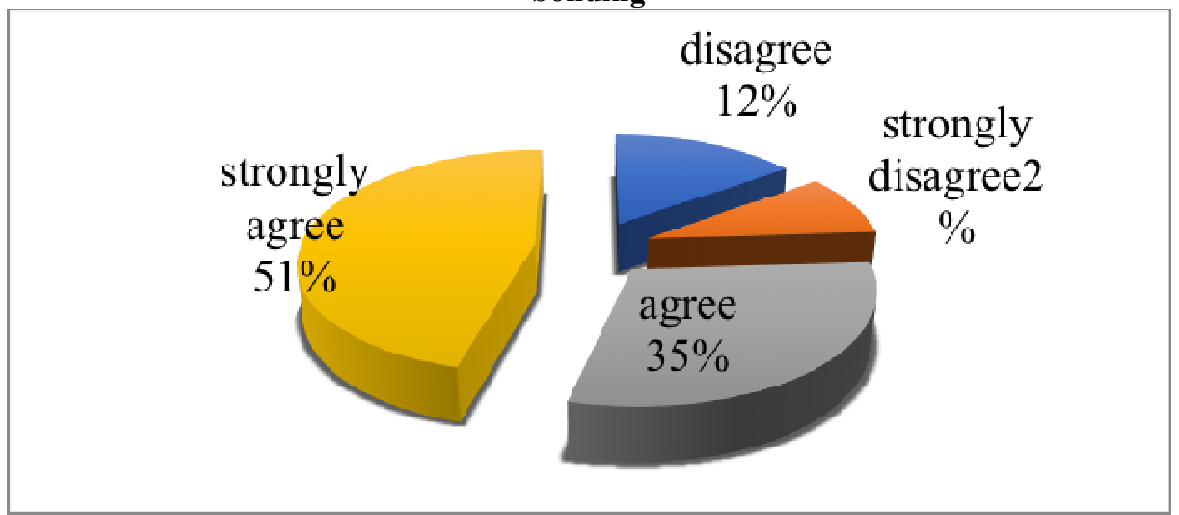

From the data, $51 \%$ strongly agreed while $35 \%$ of total respondents were of the view that lack of constant face-to-face communication negatively affects family relationships.

It can therefore be deduced that there is a reduction in face-to-face communication among family members as a result of their constant involvement with communication technologies. These findings are consistent with Stewart et al., (2014) and Achakpa-Ikyo and Ogaba-Egba (2016) who found that internet use was linked to lack of face- to-face communication among family members.

\section{Conclusion}

The present study therefore argues that while it has become easier to use technology to communicate, it has become more difficult for humans to be 'present' to the people with whom they are communicating. The argument is that genuine communication is enhanced when people mutually hear, feel, observe each other and give feedback to each other's verbal and non-verbal cues. However, such affinity is lost when communication is largely mediated; leading to the conclusion that human communication via communication technology often creates a feeling of detachment, aloofness, indifference and distance among parties. In this sense, technology compromises the immediacy of human interaction and the ways in which it is articulated including contact, proximity and the physical encounter of others.

The impact of the lack of constant face-to-face communication amongst family members on family relationships can therefore be detrimental to family relationships. The study asks the central question: how have communication technologies influenced human communication in the family? From the foregoing, there are a number of challenges affecting family communication as a result of constant use of communication technologies. While the internet has brought about greater efficiency and better information sharing in Nigeria, it has not 
necessarily enabled physical closeness and the non-verbal cues associated with face-to-face communication. In terms of ethical behavior, mediated communication has to an extent eroded the capacity of family members to manage sensitive information. People are found to be in such a hurry to share information with others outside the family that they sometimes fail to pause to make ethical judgments about the messages they are sending. What this suggests is that communication technologies are advancing far more rapidly than reasoned ethical thought can keep up with.

\section{Recommendations}

Information and communication technologies have pervaded all aspects of human communication, with tools like social media applications leading the pack. Such technologies will continue to proliferate, enabling ever more avenues of communication and changing how humans organize their lives. However, human values are central to communication and should be incorporated in the design of new technologies. Values like temperance, truthfulness, honesty and responsibility call for different ways of thinking about how technology is designed. This study recommends a review of the ten commandments of computer ethics (Computer ethics institute, 2005), first developed as a project of the Brookings Institution. The code argues that communication technologies should not be used in such a way that causes harm to other people or interferes unduly with their daily lives. Such technologies must also not be used to steal the intellectual property or spy on others. While most of these recommendations were offered over a decade ago, they are as relevant today as when they were first suggested. The focus of research in the new digital age should therefore be on how to design technologies that resolve human concerns rather than the advancement of human interaction. The digital era is an age of instant communication characterized by unbridled access to information and prompt feedback. They have changed the way people talk, write, process information, act and ultimately interact. Therefore, further research should prioritize empirical studies in the field of human communication, to gain a better understanding of the ways in which human relationships are evolving as a result of technological advancement. As individuals maximize the tremendous possibilities enabled by the spread of innovations, they should be ethical in their engagement. A key contribution of this paper is the argument that interpersonal communication flows on to affect family behaviour, which in turn affects societal behaviour. If close relationships are maintained through interpersonal communication, then such connections should happen more frequently to avoid the possibility of relationship breakdown and disintegration of society. Policymakers and researchers today face a different information and communications technology (ICT) environment as because communication technologies are far more intrusive and pervasive that they were decades ago. The nature of interactions with technologies will continuously change as technologies become more sophisticated and humans grow older. As technologies expand the range of human communication, the opportunity for face-to-face contact is decreasing steadily. A key recommendation of this paper is that in the course of engagement, communication technology and communication ethics must complement each other. In all matters of communication either directly or through mediated means, ethical judgments and decisions should be considered.

\section{References}

Aina, S. (2003). Anatomy of communications. Lagos: Julian Publishers.

Achakpa-Ikyo, P.N. \& Ogaba-Egba, R. (2016). Digital divide: A gap in interpersonal communication amongst Nigerian family relationship. GSTF Journal on Media \& Communications, 3(1), $16-22$.

Buckeridge, J. S., (2009). The ongoing evolution of humanness: Perspectives from Darwin to de Chardin. South African Journal of Science, 105, $427-431$.

Buber, M. (1965). I and thou. Retrieved from https://www.scribd.com/document/72462865/Buber-I-and-Thou

Builder, C. H. (1993). Is it a transition or a revolution? Futures, 25(2), 161-173.

Caron, A.H., Giroux, L. \& Douzou, S. (1989). Users and impacts of home computers in Canada. A process of reappropriation, In J. L. Salvggio \& Bryant (Eds.), Media use in the information age-Emerging patterns of adoption and consumer use. Hilisale, NJ Lawrence Elbaurm.

Cherry, C. (1980). On human communication: A review, a survey and a criticism. Cambridge: MIT.

Computer Ethics Institute (2005). A project of the Brookings institution. Retrieved from https://www.brook.edu/its/cei/cei_hp.hrm

Daramola, I. (2012). Introduction to mass communication. Lagos: Rothan Press.

Devito, J. (2009). The interpersonal communnication book. Boston: Pearson Education.

Dijck, J. (2008). Digital photography: Communication, identity, memory. Visual Communication 7 (1), 57 - 76.

Dunu, I. V., \& Uzochukwu, C. E. (2015). Social media: An effective tool for social mobilization in Nigeria. IOSR Journal of Humanities and Social Science, 20(4), 10-21.

Erwin, T. (1985). Nicomachean ethics. Indianapolis, IN: Hackett Publishing.

Flanja, R., \& Gaz, M. (2011). Intercultural adaptation: The case of international student exchange programmes. Retrieved from http://www.afahc.ro/ro/revista/Nr_2_2011/Articol_Flanja\&Gaz_nr2_2011.pdf 
Global information society watch (2014). Communications surveillance in the digital age. Retrieved from https://www.giswatch.org/sites/default/files/gisw2014_communications_surveillance.pdf

Haddon, 1. (1992). Explaining ICT consumption: The case of the human computer In R.

Hancock, J. T., Thom-Santelli, J., \& Ritchie, T. (2004). Deception and design: The impact of communication technology on lying behavior. In Dykstra-Erickson, E., \& Tscheligi, M. (Eds.), Proceedings of the 2004 conference on human factors in computing systems (pp. 129-134). New York, NY: Association for Computing Machinery.

Harper, R., Rodden, T., Rogers, Y., \& Sellen, A. (2008). Being human: Human-computer interaction in the year 2020. Cambridge: Microsoft Research.

Hewitt, D. (2011). The nature of human communication. Retrieved from https://in.sagepub.com/sites/default/files/upm-binaries/43992_9780857024916.pdf

Maele, V. (2003). Africa in the digital age: Opportunities and threats to the preservation of library and archival material. S. A. Archives Journal, 43, 69- 78.

Mara, P. E. (2007). Understanding man as a subject and a person: A Wojtylan personalistic interpretation of the human being. Kritike, 1 (1), 86-95.

Marwick, A. (2015). Instafame: Luxury selfies in the attention economy. Public Culture, 27 (1), 137 - 160.

McLuhan, M. (1994). Understanding media: The extensions of man. Massachusetts: MIT Press.

McQuail, D. (2005). Mass communication theory: An introduction. London: Sage.

Morrison, M. \& Krugman, D.M. (2010). A look at mass and computer mediated technologies: Understanding the roles of television and computers in the home. Journal of Broadcasting \& Electronic Media, 45(1), 135161.

Mutepfa, M. I. \& Tapera, R. (2018). Traditional survey and questionnaire platforms. Handbook of Research Methods in Health Social Sciences, 1, 1-18.

Mutula, S. M. (2005). Peculiarities of the digital divide in sub-saharan Africa. In Russell, S. E., \& Steele, T. (Eds.), Information and communication technologies and the digital divide in Africa: A review of the periodical literature, 2000-2012. Electronic Journal of Africana Bibliography, 14, 1-31.

Mutula, S. M. (2008). Digital divide and economic development. In Russell, S. E., \& Steele, T. (Eds.), Information and communication technologies and the digital divide in Africa: A review of the periodical literature, 2000-2012. Electronic Journal of Africana Bibliography, 14, 1-31.

Ndukwe, E. (2005). Furthering the digital revolution in Nigeria in the era of technology convergence. Proceedings of the induction into the technology hall of fame of the Obafemi Awolowo University, lle-Ife. Retrieved from http://www.ncc.gov.ng/archived/speeches/OAU\%20SPEECH.pdf

Neher, W. W., \& Sandin, P. J. (2007). Communicating ethically - Characters, duties, consequences and relationships. New York, NY: Pearson.

Newman, A. L., \& Bach, D. (2008). Privacy and regulation in a digital age. Retrieved from http://www18.georgetown.edu/data/people/aln24/publication-12385.pdf

Nigerian Communications Commission Report (2016). Retrieved from http://www.ncc.gov.ng/stakeholder/statistics-reports/industry-overview

Odu, O. O., Amu, E., Deji, S., Aduayi, V., Owoeye, O. \& Eyitayo, E. (2017). Perception and Attitude to Family Life Education among Parents in Osun State Nigeria. Advances In Research, 9(5), 1-8.

Pichevski, A. (2003). Ethics on the line. Southern Communication Journal, 68 (2), 152-169.

Rana, Z. (2018). Personal Growth. Retrieved 7 January 2018, from https://medium.com/personal-growth/thetwo-types-of-relationship-we-form-and-which-is-better-26339f572e $7 \mathrm{f}$

Ramanujam, R. C. (2008). Mass communication and its digital transformation. Delhi, India: APH.

Robertson, T.S. (1971). Innovative behaviour and communication. New York: NY, Rinehart and Winston.

Rouse, M. (2014). Digital divide. Retrieved October 12, 2016 from https://www. WhatIs.com.

Russell, S. E., \& Steele, T. (2013). Information and communication technologies and the digital divide in Africa: A review of the periodical literature, 2000-2012. Electronic Journal of Africana Bibliography, 14, 1-31.

Sellen, A., Rogers, Y., Harper, H. R., Rodden, T. (2009). Reflecting human values in the digital age. Communications of the ACM, 52(3), 58-66.

Silverstone \& E. Hirsh (Eds.) Consuming technologies. Media and information in domestic spaces. London: Routledge.

Smith, M., Hancock, Reynolds, L., \& Birnholtz, J. (2014). Everyday deception or a few prolific liars? The prevalence of lies in text messaging. Computers in Human Behaviour. Retrieved from http://socialmedia.soc.northwestern.edu/wpcontent/uploads/2014/10/EverydayDeceptionOrAFewProlificLiars.pdf

Smith, R. (1993). The global interactive human network: Life in the information age. Proceedings of the world future society annual conference, (691-195). Washington, WA: USA.

Spape, M., \& Ravaja, N. (2014). Social psychology of the digital age: The interpersonal neuroscience of 
mediated communication. Social Computing and Social Media, 1, 494-505.

Stewart, M., Dainton, M., \& Goodboy, A. (2014). Maintaining relationships on Facebook: Associations with uncertainty, jealousy and satisfaction. Communication Reports, 27(1), 13-26.

The Global Information Technology Report (2012). Living in a hyper connected world. Retrieved from http://www3.weforum.org/docs/Global_IT_Report_2012.pdf

Toma, C. L., Jiang, C. \& Hancock, J., T. (2016). Lies in the eye of the beholder: Asymmetric beliefs about one's own and others' deceptiveness in mediated and face-to-face communication. Communication Research, $1-$ 26

Tomecek, S. M. (2009). Animal behaviour - Animal communication. New York, NY: Chelsea House.

Vitalari, N.P., Venkatesh, A. \& Gronhaug, K. (1885). Computing in the home: Shifting in the time allocation patterns of households. Communications of the ACM, 28(5), 512-522.

Watkins, C. (2012). Digital divide: Navigating the digital edge. Retrieved from https://moody.utexas.edu/sites/default/files/watkins_1.pdf

Watzlawick, P., Beavin, J., \& Jackson, D. (2014). Principles of human communication. Retrieved from http://people.unica.it/ernestinagiudici/files/2014/03/5-pragmatic-of-communication.pdf

\section{Biography}

Ijeoma N. Onyeator is a doctoral student in the School of Media and Communication, Pan-Atlantic University. She was born in Nairobi, Kenya in 1976. She holds an M.A. in Media Communication and Technology from Brunel University Uxbridge, United Kingdom in 2003; and a BSc. in Mass Communication from the University of Lagos, Nigeria in 1999. Ijeoma became a member of the Association of Communication Scholars and Professionals of Nigeria in 2013. She is also a member of the International Association for Media and Communication Research. She received certification from the Birmingham City University for the Research Leadership Exchange Programme in 2017. Her main research interests include alternative media, human communication, citizens journalism and media philosophy. She currently a member of faculty, Pan-Atlantic University.

Dr. Ngozi Okpara is a lecturer in the School of Media and Communication in Pan-Atlantic University, Lagos, Nigeria. She was born on October $23^{\text {rd }}, 1964$ in Onitsha, Anambra state, Nigeria. She attended the University of Nigeria, Nsukka and Pan- Atlantic University, Lagos. The details of her academic qualifications are; $\mathrm{PhD}$ in Educational Psychology (University of Nigeria, Nsukka: 1995), M. ED (Educational Psychology) University of Nigeria; Nsukka: 1990, BA Ed. (1987) University of Nigeria, Nsukka, MSC in Media and Communication, PanAfrican University, Lagos, 2011. Her main areas of research are in ethics, human communication, and journalism. She has published in many academic and professional journals. She is currently the head of the Department of Mass Media and Writing. She belongs to many professional associations in Nigeria and outside Nigeria. 